\title{
PROGRAMA DE RESIDÊNCIA PEDAGÓGICA E PROGRAMA INSTITUCIONAL DE BOLSAS DE INICIAÇÃO À DOCÊNCIA: CONVERGÊNCIAS EM TORNO DA CONFIGURAÇÃO DE UM PROFESSOR SOCORRISTA
}

\author{
PROGRAMA DE RESIDENCIA PEDAGÓGICA Y PROGRAMA \\ INSTITUCIONAL DE BECAS DE INICIACIÓN A LA DOCENCIA: \\ CONVERGENCIAS EN TORNO A LA CONFIGURACIÓN DE UN \\ PROFESOR DE PRIMEROS AUXILIOS
}

\author{
Samuel Giovani dos Santos Ferreira ${ }^{1}$ \\ Luciana Pedrosa Marcassa²
}

\begin{abstract}
RESUMO: Este artigo resulta de uma pesquisa que analisou as conexões entre o Programa de Residência Pedagógica (PRP) e o Programa Institucional de Bolsas de Iniciação à Docência (PIBID), os quais integram a Política Nacional de Formação de Professores no Brasil. Tais programas se sustentam na ideia de que a formação inicial de professores deve se dar, prioritariamente, na prática, base sob a qual se desenvolvem as chamadas competências profissionais. O objetivo geral do estudo foi analisar a existência de convergências entre esses programas e suas implicações para a formação docente. Para tanto, valeu-se de revisão bibliográfica e análise de documentos sobre o PRP e o PIBID. Com base na análise dos dados, foi possível perceber que eles buscam enquadrar a formação inicial docente às orientações contidas na Base Nacional Comum Curricular (BNCC); reduzem tal formação ao treinamento de habilidades e à aquisição e certificação de competências; provocam competição entre as instituições e os pares; promovem novas atribuições às escolas e aos professores; e contribuem para naturalizar a precarização do trabalho docente e do trabalho voluntário. Tais implicações revelam a formação do professor desejado no âmbito da reestruturação produtiva e do regime flexível do capital: o professor socorrista.
\end{abstract}

PALAVRAS-CHAVE: Programa de Residência Pedagógica. Programa Institucional de Bolsas de Iniciação à Docência. Professor Socorrista.

RESUMEN: Este artículo es el resultado de una investigación que analizó las conexiones entre el Programa de Residencia Pedagógica (PRP) y el Programa Institucional de Becas de Iniciación a la Docencia (PIBID), que forman parte de la Política Nacional de Formación Docente en Brasil. Dichos programas parten de la idea de que la formación inicial del profesorado debe tener lugar, fundamentalmente, en la práctica, base sobre la que se desarrollan las llamadas competencias profesionales. El objetivo general del estudio fue analizar la existencia de convergencias entre estos programas y sus implicaciones para la formación docente. Para ello se utilizó una revisión bibliográfica y análisis de documentos sobre el PRP y PIBID. Con base en el análisis de los datos, se pudo constatar que buscan adecuar la formación inicial docente a los lineamientos contenidos en la Base Nacional Común Curricular (BNCC); reducen dicha educación a la formación de habilidades y la adquisición y certificación de competencias; provocar competencia entre instituciones y pares; promueven nuevas asignaciones para escuelas y profesores; y contribuir a naturalizar la precariedad de la docencia y el voluntariado. Tales implicaciones revelan la formación del maestro deseado en el ámbito de la reestructuración productiva y el régimen flexible del capital: el profesor de primeros auxilios.

\footnotetext{
${ }^{1}$ Escola Municipal Eugênio Pimentel Arantes, MG, Brasil. E-mail: samuelgsferreira@gmail.com

(i) https://orcid.org/0000-0003-2658-5505

2 Universidade Federal de Santa Catarina, Brasil. E-mail: lumarcassa@gmail.com

(iD) https://orcid.org/0000-0001-5313-1002

- Informações completas da obra no final do artigo
} 
PALABRAS-CLAVE: Programa de Residencia Pedagógica. Programa Institucional de Becas de Iniciación a la Docencia. Profesor de Primeros Auxilios.

\title{
Introdução
}

. Este artigo resulta de uma pesquisa que analisou as conexões entre o Programa de Residência Pedagógica (PRP) e o Programa Institucional de Bolsas de Iniciação à Docência (PIBID), tendo em vista caracterizar com maior detalhamento o que temos identificado no âmbito da formação de professores e do próprio trabalho docente, isto é, a configuração de um professor socorrista. O objetivo deste estudo foi avançar na análise do PRP e PIBID para capturar possíveis convergências que sinalizem para um reordenamento político e pedagógico na formação inicial de professores. A proposta do trabalho consistiu em ampliar os conhecimentos sobre as atuais políticas e programas de formação docente, levando em consideração o contexto marcado pelo regime de acumulação flexível do capital.

Nos últimos anos acompanhamos a formulação da Política Nacional de Formação de Professores (PNFP/BRASIL, 2017), que prospera com a aprovação e implementação da Base Nacional Comum Curricular para a Educação Básica (BNCC/BRASIL, 2017a, 2018), novas Diretrizes Curriculares Nacionais para a Formação Inicial de Professores (DCNFIP) e Base Nacional Comum para a Formação dos Professores (BNCFP) (BRASIL, 2019). São documentos que tomam a prática como princípio e a categoria competência como bases ideológicas, epistemológicas e pedagógicas para a formação docente.

Como desponta no texto referência para as DCNFIP e BNCFP:

\begin{abstract}
A prática pedagógica, na escola ou em ambiente de aprendizagem não escolar, pode ser através de monitoria, estágio, residência pedagógica ou prática clínica, que devem estar intrinsecamente articuladas com os estudos e a prática desde 0 primeiro ano. A prática pedagógica deve seguir passos cada vez mais complexos no decorrer do curso destinado à formação inicial ou continuada de professores para a Educação Básica, segundo mentoria recebida de professores responsáveis pela orientação, indo da: (I) 'familiarização inicial' com a atividade docente $\left(1^{\circ}\right.$ ano): 60 horas; (II) 'prática pré-profissional' na qual identifica os desafios do contexto pedagógico ( $2^{\circ}$ ano): 140 horas; (III) 'prática tutorada' de aula, quando já pode assumir responsabilidades no que diz respeito aos alunos, fazendo escolhas de temas de pesquisa ( $3^{\circ}$ ano) 240 horas; e (IV) 'prática engajada' em que os estudantes devem mobilizar e colocar em ação seus estudos em prática, planejando aulas e buscando resolver os problemas aos quais se propuseram durante seus anos de estudo e pesquisa ( $4^{\circ}$ ano): 360 horas (BRASIL, 2019a, p. 29).
\end{abstract}

Na Resolução 2, de 20 de dezembro de 2019, documento que define as DCNFIP e institui a BNCFP, aparece que 
a prática deve estar presente em todo o percurso formativo do licenciando, com a participação de toda a equipe docente da instituição formadora, devendo ser desenvolvida em uma progressão que, partindo da familiarização inicial com a atividade docente, conduza, de modo harmônico e coerente, para o estágio supervisionado, no qual a prática deverá ser engajada e incluir a mobilização, a integração e a aplicação do que foi aprendido no curso, bem como deve estar voltada para resolver os problemas e as dificuldades vivenciadas nos anos anteriores de estudo e pesquisa (BRASIL, 2019, p. 27).

Observa-se, inicialmente, que a formação de professores passa a ser organizada sob um currículo fragmentado e em etapas com carga horária fixa ${ }^{3}$. Além disso, o texto referência para as DCNFIP e a BNCFP (2019a) põe em evidência que é o desenvolvimento de competências que permitirá ao professor lidar com as características e desafios do século XXI, este que é caracterizado como volátil, incerto, complexo e ambíguo. Isto é:

Para tornar efetivas as aprendizagens essenciais que estão previstas nos currículos da Educação Básica, os professores terão que desenvolver um conjunto de competências profissionais que os qualifiquem para uma docência sintonizada com as demandas educacionais de uma sociedade cada vez mais complexa, que exige continuar aprendendo e cujas características e desafios foram bem postulados na Agenda 2030 da Organização das Nações Unidas (ONU) com a qual nosso país se comprometeu (BRASIL, 2019a, p. 1).

O referido documento (BRASIL, 2019a) enfatiza a importância das competências cognitivas e socioemocionais na formação dos professores. Sobre as competências cognitivas, declara que vão além do acesso aos conhecimentos, referindo-se às capacidades de selecioná-los, correlacioná-los e criá-los. Já as competências socioemocionais possibilitam compreender e constituir relações com os outros e consigo mesmo de modo confiante, criativo, resiliente e empático.

A proposição de um currículo com base na categoria competência como ordenadora das relações de trabalho e das relações educativas é reveladora do tipo de formação que se deseja na atualidade. Para Ramos (2011), com a vigência da acumulação flexível e o predomínio das concepções neoliberais de sociedade, trabalho e educação, a "competência" assume uma conotação produtiva. Sob essa orientação, importa à atividade humana enfrentar eventos, ou seja, superar barreiras que perturbam a normalidade no sistema de produção. Assim a aquisição cada vez mais precisa do "saber prático" pelo

\footnotetext{
${ }^{3}$ Neste caso refere-se a uma proposta curricular na qual predomina a supervalorização da prática em detrimento da teoria. Excessivamente prática, abdica da unidade entre teoria-prática, reflexão-ação, planejar-executar, para pautar-se em etapas de atuação voltadas à resolução de problemas imediatos no cotidiano escolar, que se assimilam a períodos de treinamento com ênfase nas práticas e experiências profissionais.
} 
trabalhador configura-se como estratégia para o processo de acumulação de capital, "como forma de garantir as constantes melhorias que precisam ser inseridas na produção dos bens ou serviços" (RAMOS, 2011, p.178).

Para Alves, Moreira e Puziol (2009), a principal função da ideologia das competências está em ocultar a relação capital-trabalho, atuando na instância educacional para produzir consensos. Ela diz respeito, por um lado, à conformação de um trabalhador com perfil flexível - com comportamentos adequados para o alcance de metas e melhores resultados - e por outro lado, à reordenação do financiamento de programas educacionais e ações governamentais, embalados pelo lema "fazer mais com menos".

Essas são algumas características que marcam a atual reforma curricular da formação superior de professores em curso no Brasil. É nesse contexto que emergem, como mecanismos da PNFP (BRASIL, 2017), o PRP e as recentes versões do PIBID. O PIBID foi lançado em 2007, passou a ocorrer em 2009 e desde então figura como uma relevante estratégia para a formação inicial de professores (PIMENTA; LIMA, 2019; PORTELINHA; NEZ; BORDIGNON, 2020). Enquanto o PRP, apesar da existência de experiências pregressas (CRUZ; SILVA, 2018; FARIA; DINIZ-PEREIRA, 2019), como uma iniciativa de abrangência nacional, é anunciado em 2017, passando a valer a partir do início de 2018.

Com o PIBID pretende-se selecionar Instituições de Ensino Superior (IES) para desenvolver projetos de iniciação à docência. São instituições e cursos elegíveis no PIBID as IES públicas, privadas sem fins lucrativos e privadas com fins lucrativos. A seleção interna dos integrantes cabe a IES, que deverá eleger estudantes matriculados e frequentes na primeira metade dos cursos de licenciatura; professores da educação básica para atuarem como supervisores desses licenciandos na escola-campo; docente da própria IES, chamado coordenador de área; e coordenador do projeto institucional, docente da IES responsável pelo projeto institucional de iniciação à docência (CAPES, 2018, 2020).

O PIBID busca aproximar o licenciando do cotidiano da profissão e do contexto em que as escolas públicas de Educação Básica estão inseridas. São objetivos dessa iniciativa: elevar a qualidade da formação inicial de professores; inserir os licenciandos no cotidiano de escolas da rede pública de educação; incentivar escolas e professores como coformadores dos futuros docentes; contribuir para a articulação entre teoria e prática. Dentre os princípios da iniciação à docência, destaca-se no PIBID: "III. intencionalidade 
pedagógica clara para o processo de ensino-aprendizagem dos objetos de conhecimento da Base Nacional Comum Curricular" (CAPES, 2018, p. 7).

Já o PRP foi anunciado pelo Ministério da Educação (MEC) em outubro de 2017. Instituído pela Portaria 38/2018 (CAPES, 2018a) e organizado pelos editais 6/2018 (CAPES, 2018b) e 1/2020 (CAPES, 2020a), tem passado por modificações. Consta na versão 2018 - 2019 (CAPES, 2018b) que se trata de uma iniciativa que pretende induzir a reformulação do estágio curricular supervisionado nos cursos de licenciatura e, se possível, reformular a prática docente nas escolas-campo. Na versão vigente, ocorre a supressão da proposta de reformulação do estágio curricular, que é substituída pela indução do aperfeiçoamento da formação prática nos cursos de licenciatura (CAPES, 2020a).

São instituições e cursos elegíveis no PRP as IES públicas, privadas sem e com fins lucrativos. A seleção interna dos integrantes cabe à IES, que deverá eleger estudantes matriculados e frequentes na segunda metade dos cursos de licenciatura (residente); professores da educação básica para atuarem como preceptores desses licenciandos na escola-campo; docente da própria IES, chamado orientador; e coordenador do projeto institucional, docente da IES responsável pelo projeto institucional de residência pedagógica (CAPES, 2018b, 2020a).

No PRP fica enfatizado o objetivo de "IV. Promover a adequação dos currículos e propostas pedagógicas dos cursos de formação inicial de professores da educação básica às orientações da Base Nacional Comum Curricular (BNCC)" (CAPES, 2018b, p. 1). São abordagens e ações obrigatórias da residência pedagógica: apropriação analítica e crítica dos princípios e fundamentos norteadores da BNCC; atividades que envolvam as competências, os conteúdos das áreas e dos componentes, unidades temáticas e objetos de estudo presentes na BNCC, com base nos quais deve-se criar e executar sequências didáticas, planos de aula, avaliações e outras ações pedagógicas de ensino e aprendizagem (CAPES, 2018b, 2020a).

Diante dessas considerações introdutórias, percebe-se que vem se alterando significativamente a formação dos professores que, no Brasil, deve acontecer à luz de uma reforma curricular que tem como princípio a "prática" e as competências como a base ideológica, epistemológica e pedagógica para esse processo. Preocupou-nos, como problemática de pesquisa, essa tendência à regulação da formação inicial de professores pelo desenvolvimento de competências profissionais a partir da prática, bem como o perfil 


\section{ENSIN@UFMS 2021}

ISSN 2525-7056

docente a ser forjado por meio do PRP e PIBID, iniciativas estratégicas no bojo da PNFP (BRASIL, 2017).

\section{Processo de pesquisa e Organização do trabalho}

$\mathrm{Na}$ busca de evidências às mencionadas problematizações, desenvolveu-se um estudo de tipo exploratório, que contou com revisão bibliográfica e análise de documentos. Segundo Triviños (1987), os estudos exploratórios permitem ao investigador aumentar sua experiência em torno de um determinado problema, servindo, também, para levantar possíveis problemas de pesquisa. Por seu turno, a revisão de literatura possibilita ao investigador familiarizar-se, em profundidade, com o assunto que interessa. Ela permite descobrir as ligações do assunto de interesse com outros problemas, o que amplia a visão sobre o tópico que se pretende estudar.

A análise documental é outra técnica de pesquisa que fornece ao investigador a possibilidade de reunir uma grande quantidade de informações sobre leis, processos e condições. Os documentos, segundo Evangelista (2008), não expressam somente diretrizes para a educação, mas articulam interesses, projetam políticas e produzem intervenções sociais, ainda que não sejam a política em si. Por essas características que marcam o trabalho com documentos de políticas, a autora reforça a imprescindibilidade de "ler as entrelinhas", fazendo "sangrar a fonte", como forma de aceder à história, à consciência do homem e às suas possibilidades de transformação.

A partir destas orientações, a pesquisa foi organizada em três procedimentos metodológicos: a) seleção e análise dos editais, documentos e legislação pertinente ao PPR e PIBID; b) revisão e balanço de literatura referente ao PRP e ao PIBID como política/programa de edital; e c) análise comparada dos dados apurados em a) e b). Esta organização permitiu localizar e selecionar os estudos e documentos mais relevantes às pretensões anunciadas.

Para o balanço de produção, levou-se em conta estudos que propusessem um debate sobre o PRP e/ou sobre o PIBID na alçada da PNFP (BRASIL, 2017) (ANADON; GONÇALVES, 2018; SILVA, 2018, 2020; FARIAS; CALVALCANTE; GONÇALVES, 2020; PORTELINHA; NEZ; BORDIGNON, 2020; COSTA; GONÇALVES, 2020). Em relação aos documentos, foram selecionados para o procedimento: Portaria 38/2018, que instituiu 0 PRP (CAPES, 2018a); edital para as últimas duas seleções do PRP, 6/2018 (CAPES, 
2018b), 1/2020 (CAPES, 2020a); e do PIBID, 7/2018 (CAPES, 2018); 2/2020 (CAPES, 2020); sem perder de vista outros documentos condicionantes da política de formação docente, a exemplo da BNCC (BRASIL, 2017a, 2018); e das DCNFIP e BNCFP (BRASIL, 2019, 2019a).

Desse arcabouço documental e bibliográfico foram extraídas as três categorias de análise que orientaram a análise dos dados: formação na/pela prática; formação por competências; e conformação docente.

\section{Desenvolvimento e Análises}

As transformações político-econômicas do capitalismo nos últimos trinta anos do século XX implicaram em mudanças radicais nos processos de trabalho, hábitos de consumo, configurações geográficas e geopolíticas, nos poderes e nas atividades do Estado. Conforme Harvey (2008), essas modificações econômicas, políticas e sociais desencadearam a transição para um novo regime de acumulação, regulamentação social e política a ele associado, chamado de acumulação flexível.

O regime de acumulação flexível significou uma ampla reorganização da produção com base na informática, robótica e microeletrônica, que tem como marca uma dinâmica flexível de organização da produção, aceleração do tempo de giro do capital, tanto na produção como no consumo. Com maior controle e regulação das relações de trabalho, resulta na diversificação e expansão das formas de exploração da força de trabalho, colocando novos requisitos para a formação de trabalhadores.

Conforme Kuenzer (2004, p.3), foram as modificações sociais que decorreram em uma sociedade atravessada pela microeletrônica, que passaram

[...] a demandar o desenvolvimento das competências cognitivas complexas, particularmente no que se refere às competências comunicativas, ao desenvolvimento do raciocínio lógico-formal, ao trato transdisciplinar, à capacidade de tomar decisões e à capacidade para transferir aprendizagens anteriores para situações novas.

Esses são os mesmos motivos que apontam para a necessidade do desenvolvimento de competências afetivas ligadas à capacidade de lidar com a incerteza, com a dinamicidade da comunicação e com o stress, características marcantes dos "novos tempos". Segundo Ramos (2011), a pedagogia das competências corresponde à reorganização da educação em geral e da escola em específico, às atitudes e práticas 
profissionais sintonizadas com a organização e o funcionamento dos processos de produção. Ela representa o comprometimento direto com os processos produtivos e com a necessidade constante de justificar a validade das ações e os resultados educacionais.

Para a referida autora (RAMOS, 2011), o termo competência evoca a excelência do fazer e do saber-fazer num dado domínio, capaz de atingir os objetivos que ao indivíduo são designados. Sinaliza, por conseguinte, para a importância das condutas e de práticas observáveis, isto é, para o desempenho humano adequado ao atual estágio de racionalidade técnico-científica da produção. Essas são as premissas que perpassam o movimento de inovação e modernização das licenciaturas, no âmbito da PNFP (BRASIL, 2017), do qual fazem parte o PRP e o PIBID.

Tanto o PRP (CAPES, 2018b, 2020a), quanto o PIBID (CAPES, 2018, 2020), expõem que a formação de professores nos cursos de licenciatura deve assegurar aos seus egressos habilidades e competências que lhes permitam desenvolver com eficácia o seu trabalho nas escolas de Educação Básica. Partem do pressuposto de que a garantia das competências profissionais ainda nessa fase de formação inicial é um ponto crucial para assegurar um sistema de ensino considerado eficaz, capaz de alavancar os índices de aprendizagem da Educação Básica e inserir o Brasil em níveis cada vez mais competitivos no cenário do capitalismo mundial.

Organizados sob essa perspectiva, PRP e PIBID revelam-se como iniciativas alinhadas às recomendações internacionais, isto é, ao projeto político e pedagógico hegemônico que reforça a predileção pelo treinamento e pelo caráter técnico de atuação do magistério. Para o Banco Mundial (2014, p. 17), o treinamento pode

[...] garantir que os professores reconheçam a importância de atrair todos os alunos para o processo de aprendizagem, estejam equipados com uma série de estratégias de ensino para conseguir isso e que cheguem à escola todos os dias preparados para usar essas estratégias, e cada minuto do tempo de aula, com eficiência.

O Banco Mundial (2014) menciona ainda que programas de treinamento pré-serviço, focados no trabalho que os professores enfrentam na sala de aula, resultam em professores principiantes mais eficazes e numa aprendizagem mais elevada para os seus estudantes. Para o Banco Interamericano de Desenvolvimento (BID/2018, p. XVI),

[...] os programas de treinamento inicial devem equipar os professores com as ferramentas de que precisam, e aqueles que ingressam na profissão devem estar preparados e prontos para promover as aprendizagens necessárias para o sucesso no século XXI. 
Tanto o Banco Mundial como o BID alegam que o treinamento de professores é uma das estratégias para corrigir pontos fracos e alavancar as competências dos atores de melhor desempenho. Algumas características encontradas tanto no PIBID como no PRP dão indícios de que esses programas são iniciativas voltadas ao treinamento de professores, como sugerido pelo Banco Mundial e pelo BID. No PIBID (CAPES, 2018, p. 8), nas características de iniciação à docência, aparece: "VIII. desenvolvimento, testagem, execução e avaliação de estratégias didático - pedagógicas e instrumentos educacionais, incluindo o uso de tecnologias educacionais e diferentes recursos didáticos". No PRP (CAPES, 2018b, p. 19), na parte que trata sobre as características essenciais da residência pedagógica, indica-se: "d) Experimentar técnicas de ensino, didáticas e metodologias com observação do trabalho em sala de aula do professor preceptor".

Esses são atributos que reforçam uma concepção tecnicista de educação que busca consolidar um profissional expert em manejar instrumentos. Buscando os meios mais adequados para atingir o êxito em suas ações, o sucesso do professor consiste na aplicação efetiva das soluções encontradas. A formação desse professor reduz-se, assim, ao treinamento para o uso de técnicas, instrumentos e ferramentas de ensino (didáticas e metodológicas). É como se, ao invés de uma sólida formação teórica, sócio-histórica, e psicopedagógica, bastasse a ele o domínio técnico do ensino. Desloca-se o domínio do processo para os resultados do trabalho, sem uma compreensão e atuação do professor na direção do desenvolvimento da formação humano-genérica dos estudantes das escolas.

No caso do PRP, essa proposta de treinamento de professores é mais evidente do que no PIBID. No PIBID o licenciando tem de cumprir uma carga horária mínima de 32 horas mensais durante, no máximo, 18 meses, que deverão ser reconhecidas pelas instituições e cursos elegíveis como horas de prática como componente curricular, de atividades teórico-práticas, ou para o cumprimento de créditos no curso. Já no PRP a carga horária do projeto deve ser distribuída ao longo dos 18 meses, de modo que o residente cumpra um mínimo de 23 horas mensais. Na sua primeira versão (CAPES, 2018b), ficava estipulado que a residência pedagógica aconteceria em 18 meses, com 440 horas distribuídas em: 2 meses para oferta de curso de preparação dos preceptores e dos estudantes para início das atividades de residência; 60 horas (4 meses) para ambientação na escola e preparação do Plano de Atividades do residente; 320 horas (10 meses) de 


\section{ENSIN@UFMS 2021}

ISSN 2525-7056

imersão, sendo 100 de regência; e 60 horas (2 meses) destinadas à elaboração de um relatório final, avaliação e socialização das atividades.

Na versão vigente (CAPES, 2020a), o PRP possui 414 horas a serem executadas em 18 meses, distribuídas em 3 módulos de 6 meses com 138 horas cada módulo. Esses módulos devem ser organizados em níveis crescentes de complexidade, sendo a data do início e fim dos módulos de decisão da CAPES. Cada módulo de 138 horas deve contemplar 86 horas de preparação da equipe, estudos sobre o conteúdo da área e metodologias, ambientação na escola, observação em sala de aula, elaboração de relatório pelo residente, entre outras atividades; 12 horas de elaboração de planos de aula; e 40 horas de regência com acompanhamento do preceptor.

Para Anadon e Gonçalves (2018), alinhados a BNCC, PRP e PIBID configuram estratégias de controle do trabalho docente, determinando o ser e o fazer docente. A ênfase nos referenciais de competências e habilidades retoma os discursos tecnicistas dos anos 1990, aproximando estudantes dos componentes que farão parte de avaliações externas; define uma supremacia da prática nos cursos, que pode levar ao esvaziamento de áreas fundamentais que problematizam os processos de aprender; incide diretamente na autonomia das universidades em relação aos cursos de licenciatura. Assim, "são processos que disputam as subjetividades professorais procurando construir docentes de uma forma bastante particular" (ANADON; GONÇALVES, 2018, p. 2).

Silva (2018) destaca que, à luz da BNCC, PRP e PIBID se orientam pelo pragmatismo na concepção de formação de professores, representando um governo que adere a uma política neoliberal influenciada por organizações internacionais. Para essa autora, a vinculação dos programas de formação de professores ao currículo da Educação Básica permite a relação direta com avaliações em larga escala, desarticula a teoria e a prática, ao propor espaços de formação diferenciados, reduzindo o conhecimento pedagógico à aplicação técnica dos conceitos da BNCC, promove a padronização da formação social, através da aquisição de competências que sugerem um conjunto de procedimentos, e transfere a mediação das ações de formação das IES para um controle direto do MEC/CAPES, fragilizando a autonomia universitária, dentre outras questões problemáticas. 
Costa e Gonçalves (2020) debatem o PRP relacionado a PNFP. Concluem as autoras que o PRP vem ao encontro de premissas tecnicistas do fazer docente, o que demonstra em sua essência uma visão pragmática da formação de professores:

Ao tratar sobre a necessidade de se proporcionar o desenvolvimento de novas competências profissionais ligadas somente à prática, o PRP atribui ao papel do professor um caráter tecnicista que visa apenas o desenvolvimento de habilidades e desloca o lugar do conhecimento enquanto apropriação da realidade. [...] O PRP vem ao encontro das premissas que propõem para a formação de professores um manual de como fazer, ao invés, de proporcionar que o processo formativo seja constituído pela valorização das vivências em sala de aula e sua integração com os conhecimentos teóricos. Isto se explicita quando o PRP em suas abordagens e ações obrigatórias recorre a apropriação analítica da BNCC, de seus princípios e fundamentos (COSTA; GONÇALVES, 2020, p. 317).

Em decorrência dessas considerações que apontam para a existência de um processo de controle e regulação da formação docente ligada ao PRP, revela-se para a educação uma pedagogia de resultados, que objetiva apenas o financiamento do que traz retorno. Isso se reflete não apenas na formação, mas também na responsabilização dos docentes e das instituições formadoras pela qualidade da educação. Em vista disso, Costa e Gonçalves alertam (2020, p. 319) para os efeitos do PRP que se anunciarão aos poucos,

[...] em processos de sucateamento das instituições públicas de formação inicial através do corte de investimentos, de culpabilização e responsabilização da formação inicial pela má qualidade da Educação Básica no país, de desvalorização docente e, principalmente, em processos de concessão das instituições públicas à iniciativa privada.

Farias, Cavalcante e Gonçalves (2020, p. 101) apontam que do PRP sobressai uma ênfase na dimensão prática da formação, "com ênfase no aprendizado instrumental e de matiz pragmático", evidenciando tendência das políticas neoliberais de imposição de orientações curriculares. Tal questão também é enfatizada no estudo de Silva (2020), que sinaliza para o caráter pragmático da PNFP e programas como o PRP e o PIBID. Para essa autora, a referência da "prática" que orienta os documentos normatizadores da política de formação docente revela que as metodologias devem viabilizar as competências e habilidades previstas no currículo.

Para Silva (2020), o foco na formação prática resulta no esvaziamento teórico da formação e atuação docente, na medida em que a formação de professores passa a ser conduzida e conformada pelos programas PIBID e PRP, já que o PIBID destina-se aos estudantes matriculados na primeira parte dos cursos de licenciatura, enquanto o PRP contempla licenciandos matriculados e frequentes na segunda metade dos cursos. São 
iniciativas que não devem ser menosprezadas, visto que encabeçam as estratégias da PNFP (BRASIL, 2017) para a formação inicial, dando indícios do que é pretendido pelo MEC, que demonstra propensão de seguir as recomendações internacionais. Com foco na aquisição de competências docentes e para docência, o PRP e o PIBID acusam ir além do constatado.

O Banco Mundial (2014) recomenda que devem ser postas em pauta nas políticas educacionais estratégias mais agressivas, como a certificação de professores, como forma de habilitar para a docência somente cursos e professores habilitados (para certificar e com seus certificados de competência). Para o Banco Mundial, a implementação de exames obrigatórios de certificação vinculados ao término dos programas de formação é o instrumento mais poderoso para o aumento no padrão "de excelência" dos professores. Corrobora com tal tese o BID (2018, p.152), que destaca que "a certificação é um dos instrumentos que os governos possuem para garantir a qualidade dos programas de formação de professores".

A certificação docente está vinculada à proposta de regulamentação do conteúdo, dos resultados dos programas e à habilitação de professores competentes. Conforme o BID (2018, p. 208),

[...] os sistemas educacionais devem optar por mecanismos de certificação que avaliem o conhecimento e as competências básicas que os egressos devem ter. Além disso, é necessário estabelecer consequências claras para os programas não certificados e que elas sejam cumpridas, para que haja incentivos para implementar melhorias e conferir credibilidade ao sistema.

Como forma de alcançar o almejado, postula o Banco Mundial (2014, p. 31) que uma

[...] estratégia para aumentar a qualidade dos novos professores é ignorar totalmente as escolas com educação de baixa qualidade e recrutar professores treinados em outras disciplinas, uma prática conhecida como certificação alternativa. Isso foi fundamental para o rápido progresso da cidade de Nova York no aumento da qualidade dos professores e é amplamente usado em outros distritos escolares urbanos dos Estados Unidos que têm dificuldade em atrair professores para trabalhar com as populações desfavorecidas. Rigorosos estudos nos EUA têm concluído em geral que os alunos de professores com certificação alternativa, mais notadamente os do programa Teach for America, apresentam um resultado igual ou melhor do que os alunos de professores regularmente recrutados.

No documento em questão, o Banco Mundial adverte que, diferentemente do que acontece nos Estados Unidos, a maioria dos países da América Latina e Caribe não tem buscado para os seus professores certificações alternativas em nenhum nível, embora seja 
permitido na Colômbia e proposto no Chile e no México. Ainda assim, destaca que, desde 2007, diversos países da região

[...] vêm lançando ramificações nacionais do programa Teach For All, com base no modelo Teach for America. No Chile, Peru, México, Colômbia, Argentina e Brasil, os programas Teach For All têm recrutado os melhores graduados de outras disciplinas dispostos a se empenhar por dois anos de magistério em escolas altamente desfavorecidas (BANCO MUNDIAL, 2014, p. 31).

Os estudos de Ravitch (2011) vão na contramão do que disseminam o Banco Mundial (2014) e o BID (2018) para a formação docente na América Latina e Caribe. Para essa pesquisadora americana, o que acontece nos Estados Unidos (EUA) são reformas conduzidas pelo mercado sobre o sistema escolar americano. Trata-se de reformas de mercado empregadas nas últimas décadas, com resultados que contribuíram para agravar a crise da educação pública nos EUA. Inicialmente entusiasta dessas iniciativas, Ravitch revela sua decepção ao notar que as soluções de mercado propostas têm servido, na realidade, para erodir os valores públicos e a própria educação pública.

Para Ravitch (2011), o foco das reformas americanas está na avaliação, nos testes, na gestão de recursos e resultados, que passam a ser concebidos como soluções em si mesmas, negligenciando as dimensões pedagógicas e políticas da educação. Defende a autora que a lógica de mercado não é apropriada para prover a educação pública, pois contém finalidades distintas. Foster (2013) acrescenta ao debate em questão que as reformas educacionais postas em práticas nos EUA transformaram a educação em um vasto campo de investimentos e lucratividade para as grandes corporações empenhadas em disputar o fundo público estadunidense. Ele denuncia ainda que a ascensão recente do movimento corporativo pela reforma escolar é distinto do movimento das fundações mais tradicionais pela sua abordagem mais agressiva e voltada para investimentos.

Foster (2013) chama de "filantropia de risco", ou filantrocapitalismo, esse tipo de abordagem mais agressiva sobre o sistema educacional. Nessas corporações empresariais o dinheiro é canalizado para projetos escolhidos, sob uma abordagem de valor agregado, que exige retorno rápido com base em critérios de eficiência e eficácia empresariais. São organizações filantrópicas de risco que atuam agressivamente em sua influência sobre as políticas educacionais nos EUA. A Fundação Gates, criada por Bill Gates, da Microsoft, é uma delas, e tem investido centenas de milhões de dólares no apoio a grupos lobistas da educação destinados a pressionar a política pública americana, visando reestruturar a 
educação pública, incentivar a privatização, acabar com a estabilidade docente etc. (FOSTER, 2013).

Segundo Foster (2013, p. 103),

[...] a Fundação Gates também apoia o Teach for America (Ensine pela América), um programa que recruta candidatos diretamente das universidades, coloca-os em um treinamento intensivo de cinco semanas, e envia-os para ensinar em escolas de baixa renda, geralmente por dois ou três anos - sem o benefício de um curso de formação de professores, ou de uma aprendizagem significativa que possibilite conseguir uma certificação profissional.

Seguramente, há sempre uma tensão entre o internacional e o local, que determina as maneiras pelas quais os aspectos econômicos, políticos e culturais influenciam tanto 0 ensino quanto a formação de professores. Contudo, não é novidade que as ideias globais têm sido apropriadas e ajustadas em algumas áreas para servir aos interesses locais. Como alternativas para a formação docente, Zeichner (2013) acrescenta, além do Teach for America, o que chama de seu clone britânico, o Teach First, criado a partir do programa chamado Teach for All. Para Zeichner, são programas que representam um marco internacional importante na promoção de rotas alternativas aos modelos universitários de formação inicial de professores.

Para esse autor (ZEICHNER, 2013), tanto o Teach for America (americano) quanto o Teach First (britânico) são programas concebidos para apoiar empresários, em outros países, interessados em desenvolver formação docente nesses moldes na sua região. São programas mais curtos, mais práticos e baseados em uma formação clínica. Patrocinados pelo governo, reduzem o papel das universidades e faculdades de educação sobre a formação docente, enquanto é aberto espaço para uma gama de programas alternativos, que competem entre si. Portanto,

[...] o que vemos nos Estados Unidos é um tremendo crescimento das rotas alternativas para os cursos de formação de professores das faculdades e universidades, o que inclui iniciativas de muitas novas empresas e universidades com fins lucrativos que entraram no 'negócio' chamado 'formar professores'. [...] Esse 'empurrão' do governo nos Estados Unidos para encorajar a desregulamentação e a competição na formação inicial de professores é muito similar ao que tem acontecido, já há alguns anos, no Reino Unido e em outras partes do mundo (ZEICHNER, 2013, p. 101-102-103).

Para Freitas (2018), esses programas são cursos alternativos que visam inserir professores rapidamente na profissão. A maioria desses cursos possui o formato de estágios, os quais são elaborados para colocar jovens aspirantes ao magistério na condição de responsáveis por suas próprias salas de aula logo no início do curso. A finalidade de 
cursos com essas características está em preparar professores bons o suficiente para aumentar os resultados dos alunos em testes padronizados (ZEICHNER, 2013). Deste modo, são programas que abalam a formação docente superior nas universidades e faculdades de educação, contribuindo para a flexibilização, aligeiramento e rebaixamento da formação inicial de professores.

Conforme Zeichner (2013, p. 107-108),

[...] em muitos lugares, o desenvolvimento profissional de professores se tornou apenas um treinamento para a 'implementação do produto' alinhado com normas e testes padronizados e é cada vez mais conduzido por pessoas empregadas pelas empresas responsáveis pelos testes e editores que produzem e vendem os materiais didáticos que são comprados pelo governo. [...] A solução para o problema da qualidade do ensino é, de acordo com alguns, desregulamentar a formação de professores e abrir os portões do magistério, antes mesmo da certificação, para indivíduos que não completaram um curso de licenciatura em vez de melhorar as condições nas escolas públicas que expulsam os bons professores.

Corroboram com essa tese Pimenta e Lima (2019, p. 5), ao afirmarem que

[...] as chances de extrair lucro da desqualificação dos trabalhadores, advinda de uma formação sucateada, abrem oportunidade de negócio para os empresários da educação. A situação de instabilidade, precarização, terceirização e vulnerabilidade a que os educadores estão expostos aumenta o mercado de venda de consultorias, de certificação e promessas de empregabilidade.

Nessa acepção, a educação deixa de ser uma atividade pedagógica articulada com um determinado fim - formar seres humanos, socializar a cultura elaborada, despertar o desejo e o interesse pelo conhecimento científico, contribuir no processo de transformação social etc. - para se transformar em um negócio, em um serviço cujo fim último é, de um lado a mercadorização da educação, e de outro, a formação de trabalhadores flexíveis ainda mais explorados.

As aproximações aqui destacadas apontam para o perigo real que é a formação de professores regida pela economia de mercado, na medida em que se reduz a uma formação completamente divorciada de um projeto emancipatório de sociedade, que agora adentra com força nas universidades e busca tornar o professor bom o suficiente para implementar scripts de ensino (ZEICHNER, 2013). Tal questão merece atenção, pois refere-se ao caso da expansão desmedida das residencies nos Estados Unidos.

Shiroma (2003a) destaca que modelos de formação de professores como a residência exibem claramente qual a tônica das recomendações internacionais nas últimas décadas para a formação de professores em vários países. Com base na experiência do Reino Unido, essa autora assinala que se trata de um modelo de formação comumente 
referido como school-based teacher education, que nada mais é do que uma perspectiva que parte da docência como atividade prática que pode ser aprendida em treinamentos obtidos unicamente nas escolas. Em suma, corresponde a uma visão que reduz a formação de professores à experiência obtida na prática, na qual os professores em formação devem passar por sucessivos treinamentos.

Em vistas dessas considerações, Freitas (2018) teme que as residencies e os programas alternativos se transformem em locais de formação de um magistério fast-food. Assim, alerta que o PRP, com finalidade terminal na formação do magistério, possa ser um passo nessa direção. Entendemos que essa análise não deve desvincular-se das recentes versões do PIBID, na medida em que o PRP e o PIBID configuram-se como rotas ou caminhos alternativos que abrangem, juntos, todo o processo de formação superior de professores. São iniciativas que contribuem para a implementação do projeto político e pedagógico hegemônico já destacado, expressando, consequentemente, o rebaixamento da formação e o perfil de professor a ser formado: professor socorrista4.

PRP e PIBID possuem atividades similares ao estágio curricular obrigatório, mas têm fundamentações e condições diferentes. São programas que transitam pelos mesmos espaços institucionais onde ocorre o estágio curricular, no qual professores e estudantes se encontram na busca de formação de novos docentes. Enquanto o estágio obrigatório move-se pela obrigatoriedade, PRP e PIBID são movidos pelo aporte de verbas. Como atividades complementares, o PRP e o PIBID concorrem com as atividades pedagógicas já desenvolvidas, compensam as fragilidades estruturais das escolas públicas (como a ausência de pessoal ou de professores efetivos para determinadas áreas) e acrescentam

\footnotetext{
${ }^{4} \mathrm{O}$ termo "professor socorrista" decorre das correlações entre o PRP, a Residência Médica (RM) e as residências multiprofissionais em saúde ou em áreas de atuação de profissionais da saúde. Isso porque desde sua gênese e das experiências precursoras no Brasil, o PRP faz alusão ou tem inspiração nas residências na área da saúde, sobretudo na RM (CRUZ; SILVA, 2018; FARIA; DINIZ-PEREIRA, 2019). Na área da saúde, a residência geralmente está associada a um período de treinamento em serviço, com vistas a habilitar um profissional especialista. No campo da educação, aparece por meio de experiências pregressas ao PRP, tanto para a formação inicial quanto para a formação continuada de professores. Em ambos os casos, refere-se a um período de formação centrado na imersão do (futuro) professor ou médico especialista no campo de atuação profissional. Volta-se à aquisição de competências, atitudes e comportamentos que do médico ou do professor são esperadas diante de situações vivenciadas no cotidiano do trabalho. A ideia da residência traz, em alguma medida, um estreitamento entre educação e a oferta eficiente, eficaz, competente - de serviços educacionais. Dessa fonte de inspiração advém, também, a formação do professor socorrista, que no campo da educação pode ser vista em programas com as características do PRP e do PIBID, no bojo da PNFP.
} 
à escola e aos professores novas demandas que vão além dos compromissos já existentes no cotidiano escolar.

O PRP e o PIBID nos cursos de licenciatura não se juntam em objetivos e atividades comuns para fortalecer uma política de formação docente no país que supere a lógica fragmentada, individualista e competitiva das próprias sociedades capitalistas neoliberais. Pelo contrário, são estratégias que competem com, ou pretendem substituir, os estágios curriculares, diversificando as possibilidades de formação sob a forma de negócio e serviço. Como estratégias da PNFP (BRASIL, 2017), buscam enquadrar a formação inicial às orientações contidas na BNCC (BRASIL, 2017a, 2018), tornando-se mecanismos voltados à aquisição e certificação de competências docentes e para a docência. Assim, são programas que guardam aproximações com as experiências do Teach for America e Teach First, que se ramificam pelos diferentes países.

Outra característica que perpassa esses programas e condiz com as orientações internacionais é a racionalidade econômica. Para a versão 2018 - 2019 do PRP e do PIBID foram disponibilizadas pelo Governo Federal 90.000 cotas de bolsas, sendo 45.000 para cada iniciativa; enquanto na versão mais recente, referente ao biênio 2020 - 2021, foram disponibilizadas 60.192 cotas de bolsas, sendo 30.096 para cada iniciativa. Essas alterações resultam em um acirramento da competição por bolsas e bolsistas. Nessa perspectiva, entretanto,

[...] a lógica de programas com bolsas é colocada no programa de formação de professores com muita propensão a se produzir um clima de competição e nichos dentro da universidade e das escolas em torno de bolsas e bolsistas. As bolsas passam a ser previstas na Lei como um benefício cedido diretamente aos participantes, por meio de crédito bancário, proporcionando celeridade ao processo e estabelecendo uma relação aparentemente mais direta e pessoal do Governo Federal com os licenciandos e professores em todos os níveis (CRUZ; SILVA, 2018, p. 240-241).

Além dessa questão, percebe-se no PRP e PIBID um forte apelo ao trabalho voluntário. No caso do PRP, fica acrescido que

5.3.1 A IES poderá, a seu critério, fracionar a cota de bolsa nas modalidades de residente, docente orientador e preceptor, desde que previsto no Projeto Institucional, para ampliar as oportunidades de participação de discentes, professores da educação básica e docentes da IES. 5.3.2 O beneficiário de cota de bolsa fracionada fica sujeito aos requisitos e obrigações deste edital, mesmo nos meses em que não receber bolsa (CAPES, 2018b, p. 4).

Ante ao destacado, Pimenta e Lima (2019, p. 4) alertam que 
as prioridades das políticas neoliberais incidem negativamente sobre a formação de professores ao acentuar práticas de ensinar em detrimento de teorias e implementar sistemas de avaliação e premiação que precarizam o trabalho docente, instituindo bônus no lugar de aumento salarial. Essas e outras medidas somadas a tantas mais passam pela vida profissional dos professores sem que eles compreendam com clareza os determinantes e a intencionalidade de tais ações.

A questão da prática docente relacionada à aquisição e certificação de competências, como as bases para o treinamento em detrimento de uma sólida formação teórico-prática, promove o que Shiroma (2003) chama de desintelectualização docente. Para a autora, a desintelectualização docente é a expressão da precarização na formação do professor. Ela remete a essa formação minimalista: mais "clínica", "prática", menos teórica, preocupada exclusivamente em fornecer, de forma suficiente, os conhecimentos úteis para o "mundo real" e para o enfrentamento dos problemas imediatos.

De modo funcional às estratégias de acumulação do capital, a desintelectualização docente corresponde a um movimento que enfatiza a "qualidade", mas insiste em retirar a formação de professores da universidade. O foco dessa "formação docente" está em construir uma profissão identificada com a tarefa, isto é,

[...] uma profissão de professores bem-educados, preparados para assumir novos poderes e responsabilidades para redesenhar escolas para o futuro. [...] Ou seja, trata-se de uma política de profissionalização menos voltada à qualificação docente e mais à instituição de novas e mais sutis formas de regulação, forjando um 'novo' perfil de profissional responsável, competente e competitivo. [...] A preocupação desta reforma é modelar um novo perfil de professor, competente tecnicamente e inofensivo politicamente, um expert preocupado com suas produções, sua avaliação e suas recompensas (SHIROMA, 2003, p. 69-78-79).

Em vista do exposto, PRP e PIBID revelam a funcionalidade de uma Política de Formação de Professores que se constrói baseada em orientações internacionais; a fragilidade dos programas de formação que se projetam no âmbito dessa política, dependente de recursos destinados a CAPES para acontecer; a naturalização da lógica concorrencial por meio de bolsas, que induz a disputa por parcos recursos e financiamento, mas que se pretende robusto e permanente como modelo; o estabelecimento paulatino de novas demandas aos professores do Ensino Superior e aos professores da escola e à própria escola de Educação Básica, compensando a situação de precariedade do trabalho docente e das próprias escolas; a abertura para possibilidades alternativas de formação, sobre as quais avançam grandes corporações interessadas em lucrar com a formação docente. 
Essa "nobre" intenção das agências internacionais, na realidade, possui a finalidade de inserir toda a formação de professores na lógica de uma economia de livre mercado. Em meio a essa configuração, a formação de professores por meio do PRP, PIBID e outros programas com caráter praticista e desintelectualizante funciona como uma resposta às demandas sociometabólicas do capital, conformando um novo perfil profissional, o qual temos chamado de "professor socorrista" (FERREIRA, 2021; 2021a). O professor socorrista compactua com a proposta do professor voluntário, com a escassez e a competição por recursos financeiros. Ele é o sujeito que, munido de suas competências e habilidades em busca de sua sobrevivência, se dispõe a qualquer vaga, sob as mais precárias condições salariais e de trabalho.

\section{O professor socorrista}

[...] é o professor que está a postos diante de uma situação de emergência, podendo ocupar uma vaga mais ou menos duradoura, temporária ou por um único dia, ante a ausência de profissionais para uma determinada matéria. Ele leva consigo o seu certificado de competências, apoia-se nos equipamentos e ferramentas pedagógicas pré-formatadas, adquiridas no mercado educacional, e se dirige à unidade educacional para pronto atendimento. O professor socorrista, reconhecido pelas credenciais de experiências práticas vivenciadas em contextos como de Residência Pedagógica [e PIBID], é aquele que carrega o perfil do professor competente e eficaz, apto e flexível o suficiente para ajustar-se à dinâmica e à volatilidade do mercado, o professor conformado, tão necessário ao século XXI (FERREIRA, 2021, p. 149-150).

O professor socorrista é a expressão paradigmática do professor desejado pelas reformas educacionais. Ele deve ser um sujeito engajado, calculista, à espreita das melhores oportunidades. Ele deve ser competente, eficaz, apto e flexível o suficiente para ajustar-se à dinâmica e à volatilidade do mercado. Ele é o empreendedor que se considera empresário de si. Em busca de emprego permanentemente, ele é o ator de sua empregabilidade, o protagonista de suas escolhas. O professor socorrista é o homem cooptado ao modo de acumulação e de inovação na organização e gestão do trabalho flexível. É o retrato do trabalhador do século XXI que, com os direitos sociais e trabalhistas dizimados, desempregado ou contratado de forma precária, olha para toda essa sua perversa condição com naturalidade.

Em face do exposto, o que se revela, na realidade, é que o professor socorrista é o trabalhador assalariado que interioriza as novas normas de eficiência produtiva e desempenho individual. O professor socorrista configura-se como um sujeito capturado pela lógica da acumulação flexível. No âmbito da PNFP (BRASIL, 2017) e de estratégias a 
ela vinculadas, a exemplo do PRP (CAPES, 2018b, 2020a) e do PIBID (CAPES, 2018, 2020), o professor socorrista é o professor treinado para aplicar as prescrições presentes na BNCC (BRASIL, 2017a, 2018). Ainda que seja chamado de "profissional", nada mais é do que um instrumento da BNCC, a quem compete realizar um conjunto de procedimentos preestabelecidos com vistas a solucionar problemas cotidianos, dando respostas e apresentando resultados úteis e produtivos do ponto de vista das avaliações e dos avaliadores internacionais.

\section{Considerações Finais}

Neste texto analisamos as conexões entre o PRP e o PIBID com o objetivo de evidenciar como esses programas, no âmbito da formação docente, têm contribuído para a formação de um professor socorrista. Procurou-se identificar convergências que sinalizam para um reordenamento político e pedagógico na formação inicial de professores, considerando o contexto marcado pelo regime de acumulação flexível do capital. Com base nos resultados encontrados, podemos concluir que, no âmbito da PNFP (BRASIL, 2017) e normativos que a complementam, como a BNCC (BRASIL, 2017a, 2018), DCNFIP e BNCFP (BRASIL, 2019), PRP e PIBID configuram-se como mecanismos estratégicos para ajustar a formação docente ao regime de acumulação flexível do capital.

O PRP e o PIBID são experiências regidas por documentos que normatizam a prática como princípio e a categoria competência como as bases ideológicas, epistemológicas e pedagógicas para a formação docente. A "prática" como "saber prático" revela, na verdade, comprometimento direto com os processos produtivos. Na forma de competências, retrata a imposição de novas formas de se conseguir melhorias na produção de bens e serviços, ocultando a relação capital-trabalho para conformar um trabalhador flexível.

Tal concepção incide sobre as políticas educacionais, organizadas sob o lema "fazer mais com menos". Este é o caso da agenda internacional que recomenda predileção pelo treinamento e o estabelecimento de políticas de gestão e controle mais agressivas para os países da América Latina e Caribe, como a certificação de competências docentes e para a docência. A situação de instabilidade, precarização, terceirização e vulnerabilidade a que os educadores vão sendo expostos alimentam novos mercados de venda de consultorias, de certificação e de formação de professores. 
Essas são características que marcam a emergência de rotas/caminhos alternativos para a formação docente nos Estados Unidos e no Reino Unido, que se assemelham ao PRP e aos recentes editais do PIBID no Brasil. Com base nas experiências internacionais, a flexibilização, o aligeiramento, o rebaixamento da formação inicial e a competição entre estudantes, professores, instituições pelo financiamento da educação pública, têm sido as formas como diferentes governos têm estimulado novas empresas e universidades com fins lucrativos a entraram no "negócio" chamado formar professores.

Percebe-se, então, que PRP e PIBID convergem para a formação de um perfil de professor egresso, o qual nomeamos professor socorrista. O professor socorrista é um sujeito que se constitui indiferente à política e aos problemas sociais a ela interligados, tendo como foco exclusivo de suas ações os resultados da sua prática cotidiana. Na medida em que reflete a modelagem do trabalhador flexível na educação, corrobora, embora não tenha ciência desta sua condição, para o funcionamento do regime de acumulação flexível do capital. Com a predominância desta perspectiva, vai conformando a profissão docente de modo conveniente ao capital.

O professor que outrora tinha a autonomia do seu trabalho, vai cedendo, tornandose um mero aplicador de scripts de ensino. Para este tipo de trabalho basta uma "formação docente" minimalista: fast-food, clínica, rápida e assentada na prática. Ao que tudo indica, é este o caminho que vem sendo trilhado no bojo das políticas e programas "inovadores" e "modernizadores" encampados pelo MEC/CAPES, com base nas recomendações internacionais.

Com o exposto, espera-se ter contribuído, fornecendo subsídios teóricos, para desmitificar a naturalidade das atuais políticas e programas que emergem no contexto de acumulação flexível do capital.

\section{Referências}

ALVES, G; MOREIRA, J; PUZIOL, J. Educação profissional e ideologia das competências: elementos para uma crítica da nova pedagogia empresarial sob a mundialização do capital. Revista de Educação Educere, Cascavel, PR, v. 4, n. jul/dez, p.45-59, 2009.

ANADON, S. B; GONÇALVES, S. da R. V. Pibid e Residência Pedagógica: efeitos nos cursos de licenciatura. In: $X$ Congresso Ibero-americano de Docência Universitária (CIDU). Comunicação, Eixo temático: Currículo e Percursos Formativos, 2018, Porto Alegre. 
BRASIL. Política Nacional de Formação de Professores. Brasília, DF: MEC, 2017.

BRASIL. Resolução CNE/CP № 2, de 22 de dezembro de 2017. Institui e orienta a implantação da Base Nacional Comum Curricular, a ser respeitada obrigatoriamente ao longo das etapas e respectivas modalidades no âmbito da Educação Básica. Diário Oficial da União - DF, 2017a.

BRASIL. Resolução CNE/CP n 4, de 17 de novembro de 2018. Institui a Base Nacional Comum Curricular na Etapa do Ensino Médio como etapa final da Educação Básica. Diário Oficial da União - DF, 2018.

BRASIL. Resolução CNE/CP n 2, de 20 de dezembro de 2019. Define as Diretrizes Curriculares Nacionais para a Formação Inicial de Professores para a Educação Básica (DCNFIP) e institui a Base Nacional Comum para a Formação Inicial de Professores da Educação Básica (BNCFP). Diário Oficial da União - DF, 2019.

BRASIL. 3a Versão do Parecer (atualizada em 18/09/19). Diretrizes Curriculares Nacionais e Base Nacional Comum para a Formação Inicial e Continuada de Professores da Educação Básica. Brasília - DF, 2019a.

BRUNS, B; LUQUE, J. Professores Excelentes: como melhorar a aprendizagem dos estudantes na América Latina e no Caribe. Washington, D.C.: Banco Mundial, 2014.

CAPES. Chamada Pública para apresentação de propostas no âmbito do Pibid. Rio de Janeiro: CAPES, 2018.

CAPES. Chamada Pública para apresentação de propostas no âmbito do Pibid. Rio de Janeiro: CAPES, 2020.

CAPES. Chamada Pública para apresentação de propostas no âmbito do Programa de Residência Pedagógica. Rio de Janeiro, 2018b.

CAPES. Chamada Pública para apresentação de propostas no âmbito do Programa de Residência Pedagógica. Rio de Janeiro, 2020a.

CAPES. Portaria no 38, de 28 de fevereiro de 2018. Institui o Programa Residência Pedagógica. Rio de Janeiro, 2018 .

COSTA, C. C. D; GONÇALVES, S. da R. V. A residência pedagógica e o pragmatismo na formação docente. Revista de Estudios y Experiencias en Educación, Chile, v. 19, n. 41, p. 307-321, dez. 2020.

CRUZ, S. P.; SILVA, K. A. C. P. da. A residência pedagógica na formação de professores: história, hegemonia e resistências. Momento - Diálogos em Educação, v. 27, n. 2, p. 227-247, ago. 2018. 
ELACQUA, G. et al. Profissão professor na américa latina: por que a docência perdeu prestígio e como recuperá-lo? Washington: BID, 2018.

EVANGELISTA, O. Apontamentos para o trabalho com documentos de política educacional. Roteiro de trabalho do minicurso oferecido durante a $31^{\text {a }}$ Reunião Anual da Anped [GT15: Educação Especial]. Caxambu, MG, 19-22 out. 2008.

FARIA, J. B.; DINIZ-PEREIRA, J. E. Residência pedagógica: afinal, o que é isso? Revista De Educação Pública, 28(68), 333-356, 2019.

FARIAS, I. M. S. de; CAVALCANTE, M. M. da S.; GONÇALVES, M. T. L. Residência Pedagógica: entre convergências e disputas o campo da Formação de Professores. Revista Brasileira de Pesquisa sobre Formação de Professores, v. 12, n. 25, p. 95-108, 22 dez. 2020.

FERREIRA, S. G. dos S. A residência para a formação de professores no Brasil: CERTIFICAÇÃO DE COMPETÊNCIAS E CONFORMAÇÃO DOCENTE. Florianópolis-SC. Dissertação, Programa de Pós-Graduação em Educação. Universidade Federal de Santa Catarina, Florianópolis, 2021.

FERREIRA, S. G. dos S. A residência pedagógica e a formação do professor socorrista. Florianópolis-SC. Trabalho de Conclusão de Curso, Curso de Pedagogia. Universidade Federal de Santa Catarina, Florianópolis, 2021a.

FOSTER, J. B. Educação e a crise estrutural do capital: o caso dos Estados Unidos. PERSPECTIVA, Florianópolis, v. 31, n. 1, 85-136, jan/abr, 2013.

FREITAS, L. C. de. A reforma empresarial da educação: nova direita, velhas ideias. $1^{\underline{a}}$ ed. São Paulo: Expressão Popular, 2018.

HARVEY, D. Condição Pós-Moderna: uma pesquisa sobre as origens da mudança cultural. 17a ed. São Paulo: Edições Loyola, 2008.

KUENZER A. Z. Competência como Práxis: os dilemas da relação entre teoria e prática na educação dos trabalhadores. Boletim Técnico do SENAC, Rio de Janeiro, v. 30, 2004.

PIMENTA, S. G; LIMA, M. S. L. Estágios supervisionados e o Programa Institucional de Bolsa de Iniciação à Docência: duas faces da mesma moeda? Rev. Bras. Educ., Rio de Janeiro, v. 24, 2019.

PORTELINHA, A. M. S; NEZ, E. de; BORDIGNON, L. S. Política de Formação de Professores: reflexões sobre o pibid e programa de residência pedagógica. InterFaces Científicas, v.9, n.1, 2020.

RAMOS, M. N. A pedagogia das competências: autonomia ou adaptação? 4⿳亠丷a ed. São Paulo: Cortez, 2011. 
RAVITCH, D. Vida e Morte do Grande Sistema Escolar Americano: como os testes padronizados e o modelo de mercado ameaçam a educação. Porto Alegre, RS:

Sulina, 2011.

SHIROMA, E. O. O eufemismo da profissionalização. In: lluminismo às Avessas: produção de conhecimento e políticas de formação docente. Rio de Janeiro: DP\&A, 2003a.

SHIROMA, E. O. Política de Profissionalização, aprimoramento ou desintelectualização do professor? Rev. Intermeio, Campo Grande, MS, v. 9, n. 17, p. 64-83, 2003.

SILVA, K. A. C. P. da. Políticas de Formação de Professores: construindo resistências. Retratos da Escola, Brasília, v. 12, n. 23, p. 307-320, jul/out, 2018. Disponível em: http://www.esforce.org.br. Acesso em: 30 jul. 2021.

SILVA, K. A. C. P. da. Residência pedagógica: uma discussão epistemológica. Formação Docente, Belo Horizonte, v. 13, n. 25, p. 109-122, set/dez, 2020. Disponível em http://www.revformacaodocente.com.br. Acesso em: 30 jul. 2021.

TRIVIÑOS, A. N. S. Introdução à pesquisa em ciências sociais: a pesquisa qualitativa em educação. São Paulo: Atlas, 1987.

ZEICHNER, K. M. A mercantilização da formação de professores nos EUA. In:

Políticas de Formação de Professores nos Estados Unidos: como e por que elas afetam vários países no mundo. Belo Horizonte: Autêntica Editora, p.99-130, 2013.

\section{NOTAS}

\section{IDENTIFICAÇÃO DE AUTORIA}

Samuel Giovani dos Santos Ferreira. Mestre em Educação pela Universidade Federal de Santa Catarina (UFSC). Licenciado em Letras/Espanhol pela Universidade Estadual Paulista e em Pedagogia pela Universidade Federal de Santa Catarina (UFSC). Professor Efetivo, atuando no AEE, na Rede Municipal de Ensino de Uberlândia, Escola Municipal Eugênio Pimentel Arantes, Uberlândia, MG, Brasil.

E-mail: samuelgsferreira@gmail.com

(i) https://orcid.org/0000-0003-2658-5505

Luciana Pedrosa Marcassa. Doutora em Filosofia da Educação. Professora do Departamento de Metodologia de Ensino do Centro de Ciências da Educação da Universidade Federal de Santa Catarina, e do Programa de Pós-Graduação em Educação (PPGE/UFSC), Florianópolis, SC, Brasil.

E-mail: lumarcassa@gmail.com.

(i) https://orcid.org/0000-0001-5313-1002.

\section{AGRADECIMENTOS}

Não se aplica.

\section{FINANCIAMENTO}

Não se aplica.

\section{CONSENTIMENTO DE USO DE IMAGEM}


Não se aplica.

\section{APROVAÇÃO DE COMITÊ DE ÉTICA EM PESQUISA}

Não se aplica.

\section{LICENÇA DE USO}

Autores mantêm os direitos autorais e concedem à revista ENSIN@ UFMS - ISSN 2525-7056 o direito de primeira publicação, com o trabalho simultaneamente licenciado sob a Licença Creative Commons Attribution (CC BY-NC-SA 4.0), que permite compartilhar e adaptar o trabalho, para fins não comerciais, reconhecendo a autoria do texto e publicação inicial neste periódico, desde que adotem a mesma licença, compartilhar igual.

\section{EDITORES}

Patricia Helena Mirandola Garcia, Eugenia Brunilda Opazo Uribe, Gerson dos Santos Farias.

\section{HISTÓRICO}

Recebido em: 08/08/2021 - Aprovado em: 02/11/2021 - Publicado em: 06/12/2021.

\section{COMO CITAR}

FERREIRA, S. G. S; MARCASSA, L. P. Programa de Residência Pedagógica e Programa Institucional de Bolsas de Iniciação à Docência: Convergências em torno da Configuração de um Professor Socorrista. Revista ENSIN@ UFMS, Três Lagoas, v. 2, n. 6, p. 68-92. 2021. 